\title{
Aliphatic Halide-Carbonyl Condensations by Means of Sodium
}

\author{
By Edgar A. Cadwallader, Abraham Fookson, Thomas W. Mears, and Frank L. Howard
}

\begin{abstract}
As a part of an investigation of the synthesis of highly branched aliphatic hydrocarbons that is being conducted at the National Bureau of Standards for the National Advisory Committee for Aeronautics, the Navy Bureau of Aeronautics, and the Army Air Forces, several compounds have been prepared by interaction of alkyl halides and various carbonyl compounds in the presence of sodium. This reaction makes possible the synthesis of certain highly branched compounds not easily obtainable by other means.
\end{abstract}

\section{Introduction}

The use of the Grignard reaction for synthesis of highly branched compounds is limited by undesirable side reactions, which become progressively more pronounced as the degree of branching of the reactants is increased. These side reactions involve the reduction and enolization of the adduct rather than the desired addition of the alkyl group.

The recent work of Bartlett and Schneider [1] ${ }^{1}$ and previous work by Morton and Stevens [13] indicate that the reaction between an alkyl halide and an ester or ketone under the influence of sodium may be used to prepare certain compounds more easily than by the Grignard reaction, or may be used in some cases in which the Grignard reaction fails completely as a synthetic tool. In this paper, are described the results of a few reactions that were designed to give information concerning the scope of the reaction and the effect of various solvents and temperatures of reaction. The work of Bartlett and Schneider has been extended to include a few additional reactants.

\section{Experimental}

The apparatus used in making small-scale runs was the conventional three-neck flask of appropriate size, fitted with a stirrer, reflux condenser, and thermometer. A separatory funnel was placed at the top of the condenser. Heating and

${ }_{1}^{1}$ Figures in brackets indicate the literature references at the end of this paper. cooling of the reaction mixture was effected by application of hot or cold oil baths. In some cases, particularly with low-boiling solvents, both small necks of the flask were fitted with reflux condensers with the elimination of the thermometer.

Sodium sand was prepared batch-wise by heating a weighed amount of sodium in a purified light mineral oil until melted, and then shaking the liquid sodium vigorously in a closed Erlenmeyer flask until the desired state of subdivision was obtained. After the particles of sodium had cooled sufficiently, they were washed by decantation with three or four portions of the solvent to be used, transferred to the reaction vessel, and immediately covered with solvent.

A few of the first reactions tried in this series were conducted in $n$-pentane (boiling range $34^{\circ}$ to $38^{\circ} \mathrm{C}$ ), but later ones were conducted in isooctane ${ }^{2}$ (boiling point, $99^{\circ} \mathrm{C}$ ). It was found that the vigorous reactions were more easily controlled when the higher-boiling solvent was used. Also the use of isooctane as a solvent facilitated the use of higher temperatures for the reactions.

Bartlett and Schneider carried out their reactions by adding all of the alkyl halide to the sodium at once and then adding the carbonyl compound over a period of time. In attempting to use this

\footnotetext{
2 This is the commonly used name for 2,2,4-trimethylpentane, which is a primary standard for octane number measurements. The commercially obtained material is exceptionally pure and serves admirably as an inert solvent for reactions of this type. The common name is used throughout this paper.
} 
technique in our applications of the reaction, we often found that the reaction was so vigorous that the sodium was completely consumed before all of the carbonyl compound could be added. Apparently in these cases there is a self-sustaining reaction between the sodium and the alkyl halide that needs only a starting impetus given by the carbonyl compound. In order to minimize this effect only a small portion of the alkyl halide was added at the start of the reaction, and the remainder was mixed with the carbonyl compound for gradual addition during the reaction.

After the reaction had been carried to completion, the mixture was decomposed either by pouring it into ice water or by direct addition of water to the mixture in the flask. If any sodium was visible in the flask, the treatment with water was preceded by the addition of small amounts of ethyl alcohol. After complete hydrolysis, the two layers were separated and the organic layer washed with several portions of water. The organic substance was finally dried over a suitable drying agent. In those cases where the products of reaction were well known, only those physical constants that were deemed necessary to identify the product were determined.

Some of these reactions have been used for large-scale synthesis; the equipment used in these cases has been described previously [8].

Methyl isobutyrate, $t$-butyl chloride, methyl $n$-butyrate, isobutyl chloride, n-propyl chloride, and $n$-butylchloride were all made by standard procedures. Ethyl trimethylacetate and hexamethylacetone (2,2,4,4-tetramethyl-3-pentanone) were prepared by methods previously described [8]. Pentamethylacetone (2,2,4-trimethyl-3-pentanone) was prepared by a large-scale run of the reaction between ethyl trimethylacetate and isopropyl chloride by the method described herein. Pinacolone (3,3-dimethyl-2-butanone) [8] was prepared by the oxidation of 3,4,4-trimethyl-2-pentene [8] with sulfuric acid-dichromate solution in a manner analogous to that used previously for the preparation of 4,4-dimethyl-2-pentanone [8]. The other materials were obtained commercially.

Only constant-boiling materials that were collected from distillation in a 180 by 2.5 -cm Whitmore and Lux [16] column were used in the synthesis. Several of these columns were used; some were packed with glass helices, the others were packed with stainless steel helices, but all were equipped with the type of distilling head recently described [7].

Solvents used for the reactions were removed by distillation through these columns; the residues were distilled (generally at reduced pressures) in a Podbielniak Hyper-cal column or in a Claisen flask fitted with a short fractionating column.

Yields were calculated on the basis of the amount of carbonyl compound that was added to the reaction. Table 1 summarizes data obtained on the several products, together with results reported in the literature.

\section{Diisopropyl Ketone and n-Propyl Chloride}

Sodium sand ( $69 \mathrm{~g}, 3 \mathrm{~g}$ atoms) was added to 1 liter of isooctane in the reaction vessel. The contents was heated to $80^{\circ} \mathrm{C}$, and a solution of $114 \mathrm{~g}$ of diisopropyl ketone (1 mole) and $157 \mathrm{~g}$ of $n$-propyl chloride ( 2 moles) was gradually added. After the reaction began, the temperature rose to $95^{\circ} \mathrm{C}$, which caused considerable refluxing. The characteristic $^{3}$ greenish-black color appeared, and addition of the ketone-halide solution was continued at such a rate as to insure vigorous refluxing. Addition time was approximately 2 hours. After standing overnight the reaction mixture was hydrolyzed, and the organic layer was washed and dried. Isooctane and unreacted $n$-propyl chloride were removed by distillation, and the residue was distilled at reduced pressure (Claisen flask). There was obtained $40 \mathrm{~g}$ of recovered diisopropyl ketone, and $51 \mathrm{~g}$ of 2-methyl-3-isopropyl-3-hexanol (32\% yield). This carbinol has been prepared by George [5] in 36percent yield by the reaction of $n$-propyl-magnesium halide and diisopropyl ketone. The residue $(50 \mathrm{~g})$ was a viscious material (boiling point $\left.>200^{\circ} \mathrm{C}, n_{D}{ }^{20} 1.4590\right)$, and presumed to be a bimolecular product from condensation of diisopropyl ketone.

\section{Diisopropyl Ketone and Isobutyl Chloride}

A solution of $155 \mathrm{~g}$ of isobutyl chloride (1.68 moles) and $96 \mathrm{~g}$ of diisopropyl ketone (0.84 mole) was diluted with $200 \mathrm{ml}$ of isooctane and added

\footnotetext{
3 This reaction is visualized as starting with the formation of a sodium ketyl as the first step. This ketyl is colored an intense dark blue, blue-green. purple, or black, depending, it seems, on one or a combination of several factors. It has been noted that in several reactions tried, where reaction failed to occur, no characteristic color was observed. It is significant that this color appears first on the surface of the sodium. At this stage, if orly a very small amount of ketone is present in relation to the amount of halide, the color often disappears as the ketone reacts.
} 
TABLE 1. Reaction products

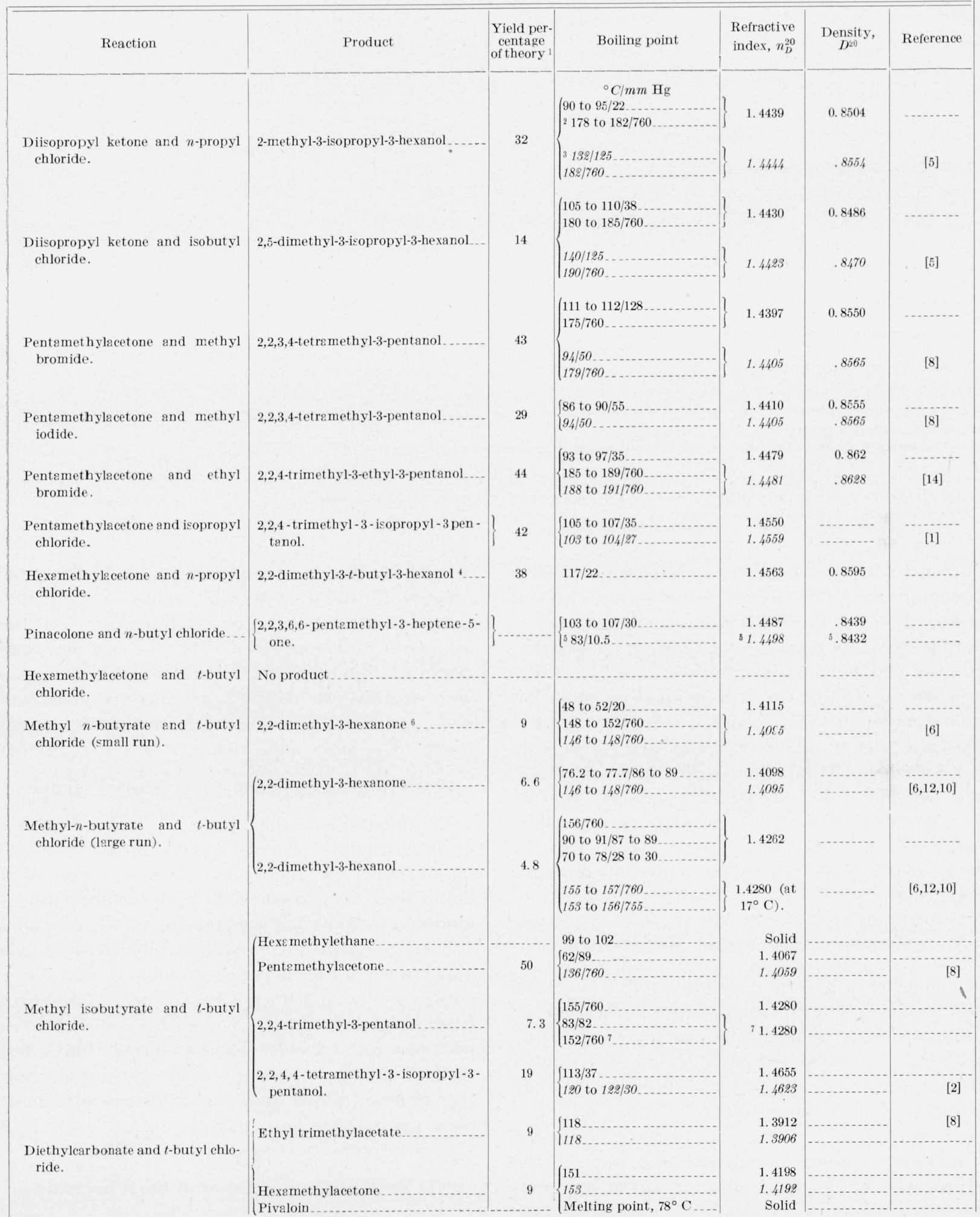

See footnotes at end of table. 
TABLE 1. Reaction products-Continued

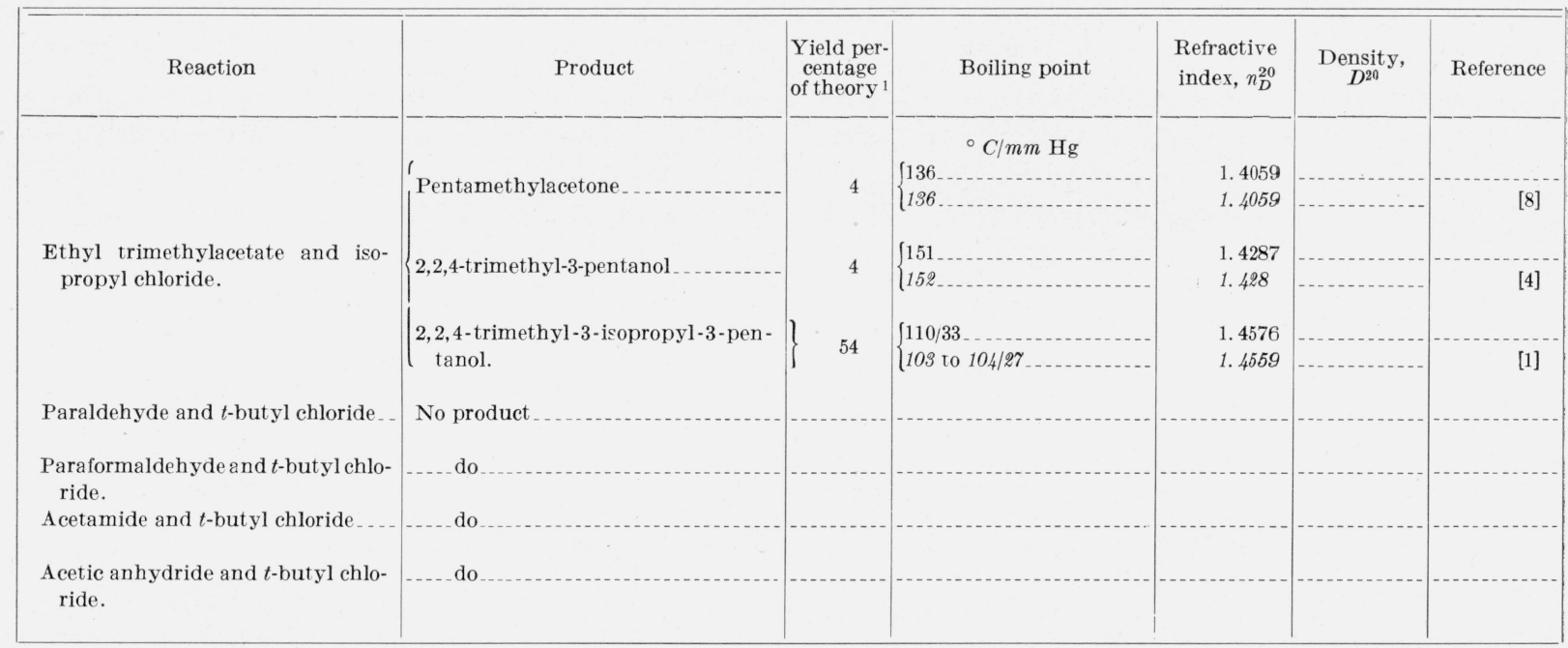

1 Yields based upon the carbonyl or ester compound.

2 The temperature conversion to $760 \mathrm{~mm} \mathrm{Hg}$ was done by a method described by Lippencott [11].

3 The data in italics are from the literature.

- A freezing point of $-10.1^{\circ} \mathrm{C}$ for this compound was made by $\mathrm{E}$. $\mathrm{H}$. Rich.

$\checkmark$ The values for a known sample of 2,2,3,6,6-pentamethyl-3-heptene-5-one, as measured in this laboratory.

${ }^{6}$ Obviously, a mixture of ketone and carbinol.

Constants from the carbinol previously prepared in this laboratory.

over a period of 3 hours to a suspension of $69 \mathrm{~g}$ of sodium sand ( $3 \mathrm{~g}$ atoms) dispersed in 1 liter of isooctane at $80^{\circ} \mathrm{C}$. The reaction mixture turned purplish blue as soon as the addition was begun, and the temperature rose quickly to $98^{\circ} \mathrm{C}$. Stirring was continued for 1 hour after the addition was completed. The reaction mixture was hydrolyzed after standing overnight, and the organic layer washed several times with water and dried. The solvent and unreacted isobutyl chloride were distilled off, and the residue was distilled under reduced pressure (Claisen flask) to give $20 \mathrm{~g}(14 \%$ yield $)$ of 2,5-dimethyl-3-isopropyl3-hexanol.

\section{Pentamethylacetone and Methyl Bromide}

A suspension of $69 \mathrm{~g}$ of sodium sand ( $\mathrm{g}$ atoms) in a solution of $128 \mathrm{~g}$ of pentamethylacetone (1 mole) and 1 liter of isooctane was heated to $80^{\circ} \mathrm{C}$. An excess of metbyl bromide was added from a methyl bromide dispenser ${ }^{4}$ through a tube extending below the surface of the liquid. The reaction began in the usual manner, with the temperature rising quickly to $98^{\circ} \mathrm{C}$, and the appearance of the blue color. Stirring was continued for 1 hour after all of the methyl bromide

\footnotetext{
${ }^{4}$ Arrow Products Co., Carlstadt, N. J.
}

had been added, and the contents of the flask was allowed to stand overnight. The reaction mixture was worked up in the usual manner, and the isooctane and unreacted methyl bromide were removed by distillation. The residue, which was distilled at reduced pressure (Podbielniak still), yielded $62 \mathrm{~g}$ of 2,2,3,4-tetramethyl-3-pentanol, ( 0.43 mole, $43 \%$ yield).

\section{Pentamethylacetone and Methyl Iodide}

Pentamethylacetone (128 g, 1 mole) and 284 $\mathrm{g}$ methyl iodide (2 moles) were diluted with 200 $\mathrm{ml}$ of isooctane and added over a period of 2 hours to a suspension of $69 \mathrm{~g}$ of sodium sand (3 $\mathrm{g}$ atoms) in $300 \mathrm{ml}$ of isooctane at $80^{\circ} \mathrm{C}$. A rapid rise in temperature occurred, followed by the appearance of the characteristic blue color. After standing overnight the reaction mixture was hydrolyzed, and the organic layer washed several times with water and dried. The solvent and unreacted methyl iodide were removed by distillation, and the residue, which was distilled under reduced pressure, (Claisen flask) gave $41.5 \mathrm{~g}$ ( $29 \%$ yield) of 2,2,3,4-tetramethyl-3-pentanol.

\section{Pentamethylacetone and Ethyl Bromide}

A solution of $163 \mathrm{~g}$ of ethyl bromide (1.5 moles) and $64 \mathrm{~g}$ of pentamethylacetone $(0.5$ mole $)$ was 
added to $72 \mathrm{~g}$ of sodium sand (3.1 g atoms) suspended in $900 \mathrm{ml}$ of isooctane. The reaction began in the usual manner with the appearance of the blue color and a rise in the temperature from $80^{\circ}$ to $98^{\circ} \mathrm{C}$. After standing overnight the reaction mixture was hydrolyzed, and the organic portion was washed and dried. Isooctane was removed by distillation, and the residue was distilled at a reduced pressure (Claisen flask) to give $35 \mathrm{~g}$ (44\% yield) of 2,2,4-trimethyl-3-ethyl3-pentanol. Nasarow [14] prepared the same carbinol in 7-percent yield by using pentamethylacetone and ethylmagnesium bromide.

A large run of this reaction has been carried out as a part of a synthesis. More precise data on the physical properties of the carbinol, its dehydration, and identification of 4,4-dimethyl-3-isopropyl-2-pentene as the dehydration product will be reported when further work, which is now in progress, has been completed.

\section{Pentamethylacetone and Isopropyl Chloride}

A solution of $64 \mathrm{~g}$ of pentamethylacetone (0.5 mole) and $98 \mathrm{~g}$ of isopropyl chloride (1.25 mole) was diluted with $250 \mathrm{ml}$ of isooctane and added to a reaction flask containing $72 \mathrm{~g}$ (3.1 g atoms) of sodium sand in $300 \mathrm{ml}$ of isooctane at $80^{\circ} \mathrm{C}$. The usual procedure was carried out, and the organic layer was worked up in the usual manner. After removing the solvent, the residue was distilled at reduced pressure (Claisen flask) to give $36 \mathrm{~g}$ (42\% yield) of 2,2,4-trimethyl-3-isopropyl3-pentanol. This carbinol was prepared by Bartlett and Schneider [1] in 6-percent yield from the reaction of diisopropyl ketone with $t$-butyl chloride by means of sodium.

\section{Hexamethylacetone and $n$-Propyl Chloride}

A solution of $142 \mathrm{~g}$ of hexamethylacetone (1 mole) and $157 \mathrm{~g}$ of $n$-propyl chloride (2 moles) was diluted with $200 \mathrm{ml}$ of isooctane. This solution was added to $69 \mathrm{~g}$ of sodium sand ( $3 \mathrm{~g}$ atoms) in $600 \mathrm{ml}$ of isooctane at $80^{\circ} \mathrm{C}$ over a period of 2 hours. A sudden rise in temperaure occurred and was followed by the appearance of the usual blueblack color in the reaction mixture. After standing overnight the contents of the flask was hydrolyzed, washed, and dried. Isooctane and unreacted $n$-propyl chloride were removed, and the residue was distilled at reduced pressure in a Claisen flask. There was obtained a 38-percent yield of 2,2-dimethyl-3-t-butyl-3-hexanol. Two analyses ${ }^{5}$ on this carbinol gave (1) C, 77.6 percent. H, 14.3 percent and (2) C, 77.6 percent; H, 14.7 percent. The calculated values are: C, 77.42 percent; H, 13.98 percent. The molecular refractions were determined: MR (observed), 58.97, MR (calculated), ${ }^{6} 58.86$.

It is presumed that the carbon and hydrogen analyses are high due to the presence of some olefinic material formed by the dehydration of the carbinol during distillation.

\section{Hexamethylacetone and $t$-Butyl Chloride}

A solution of $71 \mathrm{~g}$ of hexamethylacetone $(0.5$ mole) and $138 \mathrm{~g}$ of $t$-butyl-chloride (1.5 moles) was added to $69 \mathrm{~g}$ of sodium sand (3 $\mathrm{g}$ atoms). The reaction began at $78^{\circ}$ to $80^{\circ} \mathrm{C}$, but it did not proceed well. Considerable gas, probably isobutylene, was given off during the reaction. The ketone-halide solution was added to the reaction mixture over a period of 2 hours. The contents of the flask was worked up in the usual manner, and the solvent was removed at atmospheric pressure. The residue $(85 \mathrm{ml})$ was distilled from a Claisen flask at reduced pressure to give: 25 $\mathrm{ml}$ of residual isooctane, $36 \mathrm{~g}$ of recovered hexamethylacetone, boiling point $65^{\circ}$ to $72^{\circ} \mathrm{C}$ at 32 $\mathrm{mm} \mathrm{Hg}, n_{D}^{20}=1.4133$ to 1.4195 , and $3 \mathrm{ml}$ of heavy viscous material of unknown composition. An attempt to crystalize tri-t-butyl carbinol [1] from a pentane solution of the residue by using first an ice-salt mixture and secondly a dry ice and acetone mixture, failed to yield any solid material.

\section{Pinacolone and $n$-Butyl Chloride}

A solution of $100 \mathrm{~g}$ of pinocolone (1 mole) and $185 \mathrm{~g}$ of $n$-butyl chloride ( 2 moles) in $700 \mathrm{ml}$ of isooctane was added to $69 \mathrm{~g}$ of sodium sand (3 $\mathrm{g}$ atoms) in $300 \mathrm{ml}$ of isooctane at $80^{\circ} \mathrm{C}$ over a period of 2 hours. The reaction that ensued was similar to those already described. After standing overnight, the reaction mixture was worked up in the previously described manner. The isooctane and unreacted $n$-butyl chloride were removed at atmospheric pressure, and the residue was distilled at reduced pressure in a Claisen flask. There was obtained $43 \mathrm{ml}$ of material having these properties: boiling point, $103^{\circ}$ to

5 We are indebted to the Analytical Chemistry and Standard Samples Sections, NBS, for the carbon and hydrogen determination.

${ }^{6}$ Lorentz-Lorenz equation. 
$107^{\circ} \mathrm{C}$ at $30 \mathrm{~mm} \mathrm{Hg}, n_{D}^{20}=1.4487 D^{20}=0.8439$. The reported constants for the expected product, 2,2,3-trimethyl-3-heptanol, are boiling point, $84^{\circ}$ to $87^{\circ} \mathrm{C}$ at $13 \mathrm{~mm} \mathrm{Hg}, n_{D}^{20} 1.4409, D^{20} 0.8487$ [3]. Since the constants of the fraction obtained do not agree with the reported values, it was presumed that pinacolone had dimerized in the presence of sodium to yield, after dehydration, 2,2,3,6,6-p en t a me thy l-3-heptene-5-one, boiling point, $83^{\circ} \mathrm{C}$ at $10.5 \mathrm{~mm} \mathrm{Hg}, n_{D}^{21}=1.4498, D^{21}=$ 0.8432. A carbon and hydrogen determination gave C, 79.1 percent; H, 12.6 percent. The calculated values for the dimer are: C, 79.12 percent; H, 12.08 percent, and for 2,2,3-trimethyl-3heptanol, C, 76 percent; H, 13.92 percent. The formation of the dimer was expected rather than the addition reaction, because pinacolone, being a methyl ketone, easily aldolizes in the presence of sodium.

A 2,4-dinitrophenylhydrazone was prepared from some of this material, which melted $146.5^{\circ}$ to $147^{\circ} \mathrm{C}$. The same derivative was prepared from an authentic sample of 2,2,3,6,6-pentamethyl-3-heptene-5-one and melted at $147^{\circ}$ to $147.5^{\circ}$ C. A mixture of the two derivatives melted at $146.0^{\circ}$ to $146.5^{\circ} \mathrm{C}$. Hence the main produce from this reaction was the dehydrated bimolecular product from pinacolone.

\section{Methyl $n$-Butyrate and $t$-Butyl Chloride}

A solution of $102 \mathrm{~g}$ of methyl $n$-butyrate (1 mole) and $368 \mathrm{~g}$ of $t$-butyl chloride (4 moles) was added over a period of 3 hours to $46 \mathrm{~g}$ ( $2 \mathrm{~g}$ atoms) of sodium sand in $200 \mathrm{ml}$ of isooctane at $80^{\circ} \mathrm{C}$. After standing overnight the mixture was hydrolyzed, and the organic layer was washed several times with water and dried over anhydrous sodium carbonate. The isooctane was removed, and the residue was distilled at reduced pressure in a Claisen flask. There was obtained thereby $11 \mathrm{~g}$ (9\% yield) of 2,2-dimethyl-3-hexanone.

Since more information was desired on this reaction than was afforded by the small-scale run, a large run was made. A solution of $17.6 \mathrm{~kg}$ of t-butyl chloride (190 moles) and $7.54 \mathrm{~kg}$ of ethyl $n$-butyrate (65 moles) was added over a period of 7 hours to $6.9 \mathrm{~kg}$ of sodium sand ( $300 \mathrm{~g}$ atoms) in $10 \mathrm{gal}$ of isooctane at a temperature of $55^{\circ}$ to $60^{\circ} \mathrm{C}$ under a nitrogen atmosphere. The reaction mixture turned greenish-black during the course of the addition and evolved large quantities of gas, probably isobutylene. The reaction mixture was stirred overnight at a temperature of $56^{\circ} \mathrm{C}$.

Five gallons of 95-percent ethanol was then added over a half-hour period, and the mixture was kept at reflux temperature all day in order to remove as much as possible of the excess sodium. This was followed by 10 gal of water, which was added cautiously to the cooled reaction mixture under a nitrogen atmosphere during 6 hours. After the last traces of sodium had disappeared, the mixture was washed three times with a large amount of water. About 8 to 10 gal of organic material was obtained, which was dried over calcium chloride prior to distillation.

The isooctane was removed at atmospheric pressure, and the residue, 2,500 $\mathrm{ml}$, was submitted to vacuum distillation (Podbielniak). There were obtained $552 \mathrm{~g}$ of 2,2-dimethyl-3-hexanone (4.3 moles, $6.6 \%$ ) and $408 \mathrm{~g}$ of 2,2-dimethyl-3-hexanol $(3.1$ moles, $4.8 \%$ ) [10]. There were no fractions that could be identified as the desired product, 2,2-dimethyl-3-t-butyl-3-hexanol.

The poor recovery of starting materials is indicative of the fact that little coupling occurred; the boiling points of the coupling products are all well above that of isooctane, and they would certainly have appeared in the residue left upon stripping the isooctane. Hence their absence can only be accounted for as a consequence of side reactions. The $t$-butyl chloride was lost partly as isobutylene during the course of the reaction, and the remainder distilled with the isooctane during the stripping operation. The ester must have been lost as a consequence of alkaline hydrolysis when the reaction mixture was worked up, the hydrolysis products being discarded with the raffinates.

\section{Methyl Isobutyrate and $t$-Butyl Chloride}

In a 50-gal stainless steel reactor, $6.9 \mathrm{~kg}$ of sodium sand (300 $\mathrm{g}$ atoms) was prepared in 10 gal of isooctane. To this was added $17.6 \mathrm{~kg}$ of $t$-butyl chloride (191 moles), and the mixture was heated to $45^{\circ} \mathrm{C}$, after which $6.4 \mathrm{~kg}$ of methyl isobutyrate ( 62.8 moles) was added over a period of 6 hours. The reaction mixture was stirred overnight and hydrolyzed. The organic layer was separated, washed, and dried. Isooctane and unreacted $t$-butyl chloride were distilled at atmospheric pressure. The following compounds were isolated from the residue by distillation on a 
Podbielniak column: $59 \mathrm{~g}$ of hexamethylethane, $4,036 \mathrm{~g}$ of pentamethylacetone $(50 \%$ yield $), 599$ $\mathrm{g}$ of 2,4,4-trimethyl-3-pentanol, and $2,229 \mathrm{~g}$ of 2,2,4,4-tetramethyl-3-isopropyl-3-pentanol (19\% yield). The latter carbinol was prepared in 15percent yield by Bartlett and Schneider [1] by the reaction of pentamethylacetone, $t$-butyl chloride, and sodium.

\section{Diethylcarbonate and $t$-Butyl Chloride}

Ethyl trimethylacetate (9\% yield) and hexamethylacetone ( $9 \%$ yield) were obtained from the reaction of $277 \mathrm{~g}$ of $t$-butyl chloride (3 moles) and $236 \mathrm{~g}$ of diethylcarbonate ( 2 moles) in the presence of $92 \mathrm{~g}$ of sodium sand ( $4 \mathrm{~g}$ atoms) using petroleum ether as the solvent. There was considerable difficulty in starting the reaction, but once started the reaction became very vigorous. The sodium turned black, then bronze, and the reaction mixture thickened considerably so that additional solvent was required to permit stirring. After hydrolyzing the reaction mixture, the organic layer was worked up in the usual manner. After removing the petroleum ether, the residue was distilled in a Podbielniak column to give 0.185 mole of ethyl trimethylacetate, and 0.176 mole of hexamethylacetone.

A second run was made by using the same quantity of materials, but isooctane was used as the solvent. From the residue $25 \mathrm{~g}$ of solid (melting point, $78^{\circ} \mathrm{C}$ ), which was identified as pivaloin (melting point, $80^{\circ} \mathrm{C}$ ), and a very high boiling material were obtained. There were no fractions isolated having the properties of either ethyl-trimethylacetate or hexamethylacetone.

\section{Ethyl Trimethylacetate and Isopropyl Chloride}

In a 50-gal stainless steel reactor, $15.4 \mathrm{lb}$ of sodium sand (300 $\mathrm{g}$ atoms) was prepared in 10 gal of isooctane. To this there was added, over a period of 6 hours, a solution of 180 moles of isopropyl chloride and 60 moles of ethyl trimethylacetate. The reaction mixture exhibited the characteristic appearance of a blue color accompanied by a rise in the temperature to $54^{\circ} \mathrm{C}$. 'The reaction was kept at $50^{\circ}$ to $70^{\circ} \mathrm{C}$ by means of warm water in the kettle jacket. After standing overnight, excess sodium was destroyed by 5 gal of 190-proof ethyl alcohol, followed by ample quantities of water for hydrolysis. The organic layer was separated, washed several times with water, and dried over anhydrous calcium chloride. Isooctane was distilled off, and the residue was distilled at reduced pressure in a Podbielniak column. The following products were isolated and identified from their physical constants: 2.5 moles (4\% yield) pentamethylacetone, 2.73 moles (4\% yield) 2,2,4-trimethyl-3-pentanol, and 32.6 moles (54\% yield) 2,2,4-trimethyl-3-isopropyl-3pentanol. Distillation data are shown in figure 1.

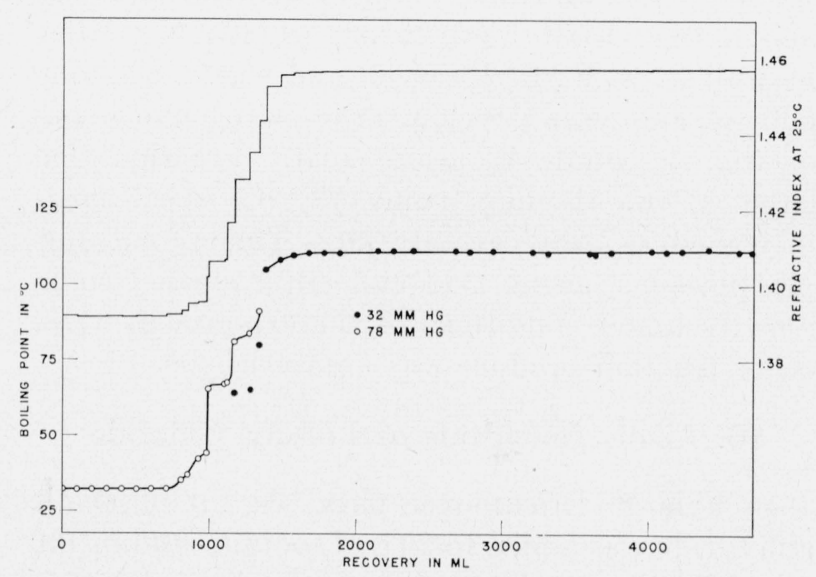

Figure 1. Results of distillation of the products from interaction of ethyl trimethylacetate and isopropyl chloride.

The small plateau in the boiling point curve, beginning at about $1,000 \mathrm{ml}$. distilled, represents pentamethylacetone; the next small plateau represents 2,2,4-trimethyl-3-pentanol. The long plateau represents 2,2,4-trimethyl-3isopropyl-3-pentanol. These curves are similar to those obtained in the other experiments.

\section{Paraldehyde, Paraformaldehyde, and $t$-Butyl Chloride}

An attempt was made to extend the BartlettSchneider reaction to include the reaction of an aldehyde with an alkyl halide. Because monomeric aldehydes aldolize under alkaline conditions, it was decided to try paraldehyde and paraformaldehyde.

A mixture of $132 \mathrm{~g}$ of paraldehyde (0.5 mole) and $138 \mathrm{~g}$ of $t$-butyl chloride ( 1.5 mole) was added in small portions to $39 \mathrm{~g}$ of sodium sand in $400 \mathrm{ml}$ of isooctane. The temperature of the reaction mixture was maintained at $80^{\circ} \mathrm{C}$ until all of the mixture had been added. There was no evidence of reaction at this temperature; consequently the mixture was heated to $90^{\circ} \mathrm{C}$ for 1 hour. After standing overnight, no reaction had taken place. The experiment was discontinued. 
A similar attempt was made with paraformaldehyde and $t$-butyl chloride as reactants, but no reaction was observed.

\section{Acetamide and $t$-Butyl Chloride}

Small portions of $59 \mathrm{~g}$ of acetamide (1 mole) and $277 \mathrm{~g}$ of $t$-butyl chloride ( 3 moles) were added to a reaction vessel containing $69 \mathrm{~g}$ of sodium sand (3 $\mathrm{g}$ atoms) in 1 liter of isooctane. The reaction was very sluggish with evolution of a gas (probably isobutylene), and the temperature did not rise above the initial temperature of $80^{\circ} \mathrm{C}$. After hydrolysis with ethyl alcohol and water, a strong odor of ammonia developed indicating hydrolysis of the acetamide to acetic acid. Fractionation gave a cut (boiling point $78^{\circ} \mathrm{C} \quad n_{D}^{20}=1.3862$ ) identified as ethyl acetate [9]. This is not surprising, since acetic acid and ethyl alcohol could esterify under conditions of the experiment. No other reaction product was obtained.

\section{Acetic Anhydride and $t$-Butyl Chloride}

In a large Erlenmeyer flask, $94 \mathrm{ml}$ of acetic anhydride was added to $23 \mathrm{~g}$ of sodium sand in 100 $\mathrm{ml}$ of isooctane. The mixture was heated to $75^{\circ}$ $\mathrm{C}$, and $217 \mathrm{ml}$ of $t$-butyl chloride was added in small amounts. From time to time the flask was heated on a hot plate. There were no visible signs of reaction, nor did any reaction occur when the contents of the flask was heated to the boiling point of isooctane (boiling point, $99^{\circ} \mathrm{C}$ ). The addition of $t$-butyl chloride was discontinued, and the reaction mixture was allowed to stand overnight. No change had taken place during the night, and the experiment was therefore discontinued.

\section{Summary}

In the study of these condensation reactions, seventeen runs were made, of which nine were of the aliphatic ketone-aliphatic halide type, four were of the aliphatic ester-aliphatic halide type, and four were a miscellaneous type. In those reactions that produced desirable compounds, the yields were as good or better than where the Grignard reagent was employed.

This reaction is apparently, applicable to compounds whose carbonyl group is sufficiently removed from influences that cause enolization, aldolization, or hydrolysis. Table 1 is a résumé of results obtained in this work.

\section{References}

[1] P. D. Bartlett and A. Schneider, J. Am. Chem. Soc. 67, 141 (1945).

[2] G. Calingaert, H. Soross, V. Hnizda, and H. Shapiro, J. Am. Chem. Soc. 66, 1389 (1944).

[3] J. B. Connant and A. H. Blatt, J. Am. Chem. Soc. 51, 1227 (1929).

[4] A. Faworsky, J. Prakt. Chim. 88, 651 (1913).

[5] Richard Stanley George, PhD Thesis, Pennsylvania State College (1943).

[6] A. Haller and E. Bauer, Compt. rend. 150, 586 (1910).

[7] F. L. Howard, Anal. Chem. 19, 144 (1947).

[8] F. L. Howard, T. W. Mears, A. Fookson, P. Pomerantz, and D. B. Brooks, J. Research NBS 38, 365 (1947) RP1779.

[9] E. H. Huntress and S. P. Mulliken, Identification of pure organic compounds, p. 378 (John Wiley \& Sons, Inc., New York, N. Y., 1941).

110] M. J. Lerodie, Ann. Chim. Phys. [9] 16, 369 (1921).

[11] S. B. Lippencott and Margaret M. Lymen, Ind. \& Eng. Chem. 38, 320 (1946).

[12] R. Locquin and L. Leers, Compt. rend. 178, 2097 (1924); Bul. soc. chim. [4] 39, 434 (1926).

[13] A. Morton and J. R. Stevens, J. Am. Chem. Soc. 53, 2244 (1931).

[14] I. N. Nasarow, Ber. deut. chem. Ges. 69B, 21 (1936).

[15] F. C. Whitmore, J. M. Church, and R. U. McGrew, J. Am. Chem. Soc. 56, 176 (1934).

[16] F. C. Whitmore and A. R. Lux, J. Am. Chem. Soc. 54, 3451 (1932).

Washington, January 26, 1943. 